\title{
Transformation of legal impact in the context of the modern information and technological structure (case study of the relations connected with genomic information)
}

\author{
L. N. Berg* \\ Ural State Law University, Yekaterinburg, Russian Federation
}

\begin{abstract}
The article is devoted to a crucial theoretical issue of the impact transformation under the influence of digital technologies. It is necessary to distinguish the process of law evolution in general and legal impact in particular, which presupposes a gradual, "dosed" change in the regulatory legal framework of the state in the direction of its greater adaptation to changing socio-economic and political realities from a more radical version of changes - from the transformation of legal impact under the influence of digital technologies and new qualities acquired by the information society. Legal impact in the digital environment demonstrates not only a new type of subjects, previously unknown to the classical paradigm of law, but also a special type of legal ties. From a legal point of view, the relationship pattern is of contractual nature on the Internet, reflecting the conventional process of interaction of quasi-subjects of law, which corresponds to the nature of almost any network interaction. However, the specificity is that norms are formed; and they contain self-regulation rules and have a legal impact on the subjects of network communication. The transformation of legal impact in the above sense presupposes qualitative changes in legal impact that are local in time, but reactive (accelerated) in intensity, accompanied by the complication of the legal impact organization, the emergence of new components under the influence of technological factors and, accordingly, new functions. The objective is to demonstrate the vector of changes in the contemporary theory of legal impact and acquire a new look for it. We use the data and material of modern characteristics of society to solve the problem. The transformation of legal impact occurs under the influence of changes in the legal and social systems having occurred as a result of the reconfiguration of social objects, which are traditional areas of legal impact, and owing to the forced transformation of legal means used by the state. The basic features of such transformation are revealed by the example of a theoretical comprehension of the "genomic information" concept and the attitude of the legislator to it. The result of the study is the conclusion that the transformation of legal impact is a sequential system of organizational, legal, mental shifts (innovations), which provide for the creation of new components of legal impact that do not coincide with their previous structures with a supplementary (or new) set of functions.
\end{abstract}

\section{Introduction}

The study of the legal impact features on society and social relations, the research of the process essence, the functions, methods and ways of legal impact on modern institutions and activities of subjects is carried out by various legal sciences, which use the paradigm of legal impact formed by the classical theory of law as a theoretical basis in the last quarter of the $20^{\text {th }}$ century [1]. We have to admit that the existing theoretical models of legal impact - legal-psychological, right-positivist - often capture abstract mechanisms schematically that are used or can be used in certain historical conditions.

According to researchers, modern society is a complicated conglomeration of socio-economic, demographic, ecological and technological processes and phenomena, not only multidirectional and multidimensional, but also contradictory. States, the driving mechanisms of development, under the influence of growing problems are rapidly differentiating in their ability to adequately respond to the challenges of the modern era. "Strong states" are pulling ahead (F. Fukuyama) primarily due to technological power, the ability to impose their beneficial vectors of sociopolitical and economic development on other states. The first quarter of the $21^{\text {st }}$ century is characterized by the differentiation of societies and states, when each of them functions, develops and dies according to its objective laws in correlation, which is given by belonging to one type or another. Indeed, when archaic, traditional, conservative and innovative types of societies function simultaneously, this requires appropriate consideration by state bodies when determining legal policy and a model of legal impact on social processes in a particular society. Therefore, the legislator, exercising legal influence, must be aware of the society type (agrarian, 
industrial, post-industrial, etc.) for which he creates normative legal acts, and whether the model of legal influence chosen by him corresponds to the nature of this or that society. This is an axiom. Otherwise, a situation occurs when legislation is developed and implemented without considering the nature of society, which is subject to legal influence from the state.

The objective is to demonstrate the vector of changes in the contemporary theory of legal impact and acquire a new look for it. We use the data and material of modern characteristics of society to solve the problem. The transformation of legal impact occurs under the influence of changes in the legal and social systems having occurred as a result of the reconfiguration of social objects, which are traditional areas of legal impact, and owing to the forced transformation of legal means used by the state.

The global and natural tendency of modern civilization is the impact of technique and technology on society, when change in the consumer behavior model took place in the last decade. The information society, where know-how and information technology become the main driving force behind the transformation, has replaced the consumer society. The key "marker" of the technotronic era is information, the scientific concept of which, according to philosophers, has "the same ontological status as energy, time and space." [1].

Using the theory of conceptual series developed by A.M. Vasiliev, consistently revealing the content of the "information" concept, it is essential to dwell on such concepts as "legal information" and "genomic information." The emergence of the latter concept and its characteristics as a general scientific one also reflects modifications in society caused by a change in the technological structure.

Thus, the concept of "legal information" includes information and other data that are contained in legal acts, regulatory and technical, reference and scientific materials [2]. Moreover, legal information includes data of a legal nature created and transmitted by subjects in the course of their interaction, streamlining their activities [2].

Typically, genomic information means personal data, which involves information about certain fragments of DNA of an individual or an unidentified corpse. The given definition, enshrined in the Federal Law on State Genomic Registration, is specific and narrowly focused on identifying the offender personality, disclosing, and preventing crimes.

The state strives to respond the upcoming technological "breakthroughs", taking into account the specific manifestations of new features in the society nature, and changes in the standards of mass behavior. As a result, there are theories, projects, programs, strategies that express new approaches of the state to the practice of rule-making in new conditions. However, the desire of the state to keep pace with the onset of innovations becomes more obvious; therefore, the issues of theoretical justification of the state practical steps look more problematic. The need to formulate a new theoretical model of legal impact in modern technological and social conditions is felt clearly. The model should be called the "information technology model of legal impact." There can be many models of legal impact, and they all have prerequisites for their existence and, apparently, meet the goals of knowledge of legal processes taking place in society. Most of these models do not completely correspond to the tasks characterizing the issues of legal impact in the context of technological and informational modernization. The formulated scientific task is quite complicated, since it requires not only the use of appropriate research methods, but also changes in the dominant traditional matrix of legal impact (theoretical model), which does not fit into the context of contemporary realities.

In particular, the emergence of a new concept of "genomic information" as a type of legal information and its theoretical comprehension predetermine the need to analyze the current legislation and the model of legal impact due to its characteristics. In this sense, the Russian legal system is not the single one that has faced the problem of changing the technological structure and, as a result, the emergence of new concepts and categories. For instance, according to Mexican General Law of Health of 1997, the human genome is defined as "the genetic material that characterizes the human species and contains all human genetic information, which is considered as the basis for the fundamental biological unity of man and its diversity" [3]. In accordance with the Indian Code of Ethics in the biomedical field, the genome is characterized as genetic material related to DNA or any other material that carries hereditary information in every cell of the body. It consists of unique, single copies of genes that make up approximately $10 \%$ of the DNA. The general information content of a person is known as the "genome" [4]. Definitions of the "genome" concept given by foreign legislators from a theoretical point of view are examples of applying the information approach in the study of legal impact.

\section{Methods}

The thesis that society as an object of modern legal impact is complicated, dynamic, changing and methodologically initial. In this regard, French philosopher and sociologist E. Morin noted, "The comprehension of complexity requires a reform of understanding" [5].

It is obvious that this imperative also means a probable reconstruction of the methodological field, namely, it is required to search for and apply new methods of cognition capable of "grasping" the dialectically changeable essence of modern society and forms of state response to new phenomena. Traditional methods of cognition associated with the analysis of law, state and society, reduced to formal legal methods being positivist able to give only some structural schemes, devoid of meaningful properties, dynamic features and shades.

For example, research on legal impact conducted in the classic right-positivist period was analytical and synthetic in nature, which serves as a confirmation and a 
classic example of a formal legal approach. The authors paid much attention to the conceptual and terminological analysis of legal impact, while the phenomenon of legal impact, as well as its essential characteristics, remained on the periphery of the authors' research. The reason is that the phenomenon of legal impact was traditionally studied in isolation from the object, which is the technological field of application of the chosen methods.

Modern era, characterized by the rapid development of technology, provides not only new forms of interpersonal relations based on remote interactions, but also another type of communication with a machine (in its broad sense), when the subject spends most of the time in active interaction behind a computer monitor or other device. The nature of the subject social behavior changes, it can be called "virtual here-and-now presence."

The proposed term designates such a presence as a transcendental character, because the subject gets the opportunity to simultaneous presence in various social relations. He can conclude a deal, write an official statement with an electronic signature, or commit a delict staying at home. In other words, the set of typical situations that should be covered by the general scale of behavior - legal norms, state legislation is changing. Law quite easily coped with its main mission - to establish a general scale of behavior, to exercise legal impact influencing the consciousness and motives of the subject's behavior, directing him in those socially significant landmarks that society needed before the technotronic era, when the standard behaviors were not so numerous and variable [6].

Legal reflection, implemented by the theory of law and the state, faces significant difficulties in the information space caused by innovations that have spread in contemporary society under the influence of modern digital technologies. It is quite complicated for the state and society to ensure efficient legal impact in the new social and economic situation, in the context of permanent technological modernization.

The reason is that the list of means and channels of influence allowing one to hope that the motives of legitimate behavior will prevail in the minds of all strata and groups (for example, in the case of struggle or competition between a legal and illegal motive [7]) is rather traditional and no longer gives the desired effect. Consequently, the task of theoretical science of law and the state is to update the methodological arsenal and develop new paradigms that correspond to the acuteness of the present moment. This is a natural process, since "new scientific concepts, new approaches, methods of scientific research appear in science when there is a qualitative transformation of fundamental bases of science" are in response to the era challenges [8].

\section{Results}

The application of traditional methods of legal knowledge contributed to the development of a model, which the author can conditionally call "the traditional model of legal impact." This term has a clear content and certain boundaries: it means the awareness and scientific and rational support of certain scientific theories and types of legal practices by the scientific elite. In particular, the traditional model of state functions, the traditional model of lawmaking and law enforcement, the traditional model of legal responsibility have been and remain thereof. The traditional model in science can be interrupted, supplanted or updated, but its significance lies in the fact that it retains previous outlines of its existence in new models of jurisprudence.

The traditional model (legal impact) having developed in Russian jurisprudence in the second half of the $20^{\text {th }}$ century, implies that legal impact is carried out by proclaiming state policy in law, by educating members of society and in the form of regulating public relations in order to establish and develop public order $[9,20]$.

The generally accepted position boiled down to the fact that the indicated goals are achieved through regulatory legal acts [10-11]. Some authors discuss the effectiveness of legal norms as one of the main instruments of legal impact [12-13]. The realities of the first quarter of the $21^{\text {st }}$ century convince that the existing traditional model needs to be rethought. The primary reason lies in the technological impact of information technology on all spheres of society. As a result, the information space is being formed as a new area of application of human activity. Information is a valuable product (goods, service). As a result, there is an increase in the number of entities involved in the provision of information services. The areas of application of scientific and technological progress achievements are expanding: the Internet, smartphones, and computers. Electronic media are replacing paper media. A development of digital markets, electronic economic and social networks is observed. The question is pertinent: what pattern determines the decisive influence of technical innovations on changes in society: technology is "soulless", it is applied and used according to its own rules, different from social impact, and society, on the contrary, is anthropic and develops due to the laws of biosocial organization?

Responding the above question, which is significant for comprehending the features of the legal impact, it is worth recognizing that the emerging technological modernization that ensures the emergence of innovations, modifications or the borrowing of technologies, leads to the formation of new social relations regarding their application and use, leads to the emergence of new social institutions, within the framework of which the corresponding rules of interaction and use (application) of new technologies and devices are formed.

Therefore, a special social organization arises; and it is based on the generality of technical norms and the widespread use of information technologies. In the given situation, information acts as a means of additional "gluing" of society in a new technological order. Previously, ideology, power or religion could act as a connecting means of society into a single whole, and presently, new social practices related to the use of information act in this capacity. Hardware and software 
complexes of organizational, informational and technical solutions linking people through electronic communication channels around the world, give the effect of a single whole, the effect of a universal transcendental connection of a single humanity in a single information space. In the issue, there is a process of formation of a new community - a technotronic society, which objectively requires an appropriate legal impact. As noted in the literature, "society should strive for the informational condition, and information parameters of society should be extended to all constituents of civil society ... information society and the state in its geopolitical aspect coincide" [14].

Reasonable fears that information, including genomic one, can be used for illegal purposes arise simultaneously with positive changes that characterize the emergence of new technotronic society. This predetermines the need to develop special juridical instruments for the legal protection of genomic information as an element of legal impact. In particular, wrongful disclosure of information obtained from the human genome can lead to genetic discrimination. The US National Institutes of Health defines genetic discrimination as "the special treatment of a person by an employer or insurance company because they have a gene mutation that causes or increases the risk of a hereditary disease (disorder)" [15].

For example, a woman was deprived of insurance after submitting medical documents on a preventive operation to an insurance company, due to the fact that "she had a BRCA1 gene mutation associated with an increased risk of breast cancer" [15].

Similar situations can also impede employment or career advancement, mortgage lending in cases of a subject's predisposition to Alzheimer's disease or other serious illnesses.

The legal protection regime is established in the Federal Law "On State Genomic Registration in the Russian Federation" for violation of the rules for obtaining, recording, storing, using, transferring and destroying biological material and processing genomic information. Analyzing article 10, the legislator implies the following types of legal liability: criminal (for example, under the following articles of the Criminal Code of RF: Art. 167 "Intentional destruction or damage to property", Art. 168 "Destruction or damage to property by negligence", Art. 272 "Illegal access to computer information") [16], administrative (for example, Art. 13.11 Code of Administrative Violations of RF "Violation of the procedure established by law for the collection, storage, use or dissemination of information about citizens (personal data)", Art. 13.14 Code of Administrative Violations of RF "Disclosure of information with limited access") [17], civil and disciplinary.

It seems to be evident that the current legislation does not provide protection of relations associated with genomic information from the above genetic discrimination and other forms of infringement on protected rights and legitimate interests that are atypical for the traditional model of legal impact.
The consequences of the above anthropogenic influences are such that the legal impact in the last 5-7 years takes not only the form of normative legal provisions in accordance with the official doctrine of law and the prevailing paradigm of legal impact. The socalled non-legal sources, owing to modern technical progress, are "connected" to the process of influencing the consciousness of subjects, in addition to the official norms created by the state. The norms are called "digital norms" - these are rules of behavior in the electronic Internet environment, which have the status of the most influential and authoritative rules in the digital world. They include guideline-norms, advice-norms, reputation norms, other techno-social and cultural norms (for example, rules for the use of cloud technologies, digital platforms when buying and selling goods and services, status and rating assessments of participants in network communication, etc.). The peculiarity of the enumerated rules is that they are created by subjects of network interactions, developers and administrators of digital platforms. According to the author, the significance and proportion of the indicated type of rules will increase, and the role and importance of official sources of law will decrease. It should be borne in mind that in 2019 the number of users in this area reached 3.5 billion people.

Another new feature of legal impact is that it gradually takes on forms that differ from the ordinary forms of law - normative legal complexes of legislation as a system of signs. Law and norms are transformed, turning into a logically built set of visual images or virtual, but obligatory patterns of behavior, created by a program ("digit"), and rules that contain a certain meaning guiding behavior (actions). There is a process of converting a text containing instructions into signs of a various type, namely, into visual images. Consequently, informational "media visualization" of legal impact is gradually taking place. This refers to the case when, for example, a consumer enters a digital platform and further demonstrates his or her behavior under the influence of norms - visual images.

Visualization of law is a semiotic transformation of legal impact, in which the source place is occupied by specially created sites containing visual regulators-rules. For example, sites comprising many pictures, videos, illustrations, tables, text are united by the concept of "data." A new quasi-legal semiotic system of law influence, guided by the interface of a program or digital platform, is created in this way.

As noted in the specialized literature in connection with the analysis of the "digital interaction" role of subjects: "The future ... will include an increasing number of users - physical objects (things), which will lead to the need for improving interactions between subjects and physical objects, between groups of physical objects (things)" [15].

We believe that in a number of areas of legal impact, the place of the legislator can be taken by the owner (holder) of the digital platform, who will use not only his economic power, but also "monetize" this power into political one, creating norms and rules of behavior within the framework of the platform he has created, and society can take the role of consumers. However, no one 
guarantees that this software-digital product will be without evaluation, or imposed values and norms that coincide with those that come from the official authorities. In this context, the digital world cannot be recognized as an area of total freedom. On the contrary, participants in the digital environment are programmed for certain behavior, which is directed not so much by the state (through a well-known website of public services, etc.), as by corporations using technologies of super-perfect digital structures [16].

In modern conditions, legal relations reflecting the renewal of the standard set of law subjects [17] and a set of norms, act as components that form the basis of the theoretical model of legal impact. The former include subjects who hide their user data, identifying themselves as "noname" or "anonimus." These are "quasi-subjects of law" - bloggers, content distributors on the Internet, etc.

Legal impact in the digital environment demonstrates not only a new, previously unknown to the classical paradigm of law, type of subjects, but also a special type of legal ties [18-20]. From a legal point of view, the nature of relationships on the Internet is of a contractual nature, reflecting the conventional process of interaction of quasi-subjects of law, which corresponds to the nature of almost any network interaction. However, the specificity is that norms containing self-regulation rules, which have a certain legal impact on the subjects of network communication, are formed [21].

An essential theoretical problem is the issue of the of legal impact transformation under the influence of digital technologies [22]. It is necessary to distinguish the process of the law evolution in general, known to any scientist-legislator, and legal impact in particular, which implies a gradual, "dosed" change in the regulatory legal framework of the state in the direction of its greater adaptation to changing socio-economic and political realities from a more radical version of changes - from transformation of legal impact under the influence of digital technologies and new qualities acquired by the information society $[23,24]$. The transformation of legal impact in the above sense presupposes qualitative changes in legal impact that are local in time, but reactive (accelerated) in intensity, accompanied by the complication of the legal impact organization, the emergence of new components under the influence of technological factors and, accordingly, new functions [25-27].

\section{Conclusion}

In recent years, the process of legal impact, generated by the state, presupposes a qualitative transition from the old "scheme" (model) of legal impact to a new model within the framework of the general logic of changes in the process of law formation and law-making, conditioned by new qualitative characteristics of society [28]. The transformation of legal impact is a sequential system of organizational, legal, and mental shifts (innovations), which provide for the creation of new components of legal impact that do not coincide with their previous structures with a supplementary (or new) set of functions.

The study was carried out with a grant from the federal budget on the implementation of a scientific project "Identification of regulatory problems in the use of genetic and genomic information. Preparation of scientifically based proposals for changes in the Russian legislation" (topic code FEUW-20200005).

\section{References}

1. I.V. Silakova, Encyclopedia of Methodologies of Political Science, Issues of philosophy, 8, 207-214 (2019).

2. L.N. Berg, The theory of legal impact: monograph, p. 309 (2021).

3. R. Yotova, The Regulation of Genome Editing and Human Reproduction Under International Law, EU Law and Comparative Law (2017). Retrieved from: https://www.nuffieldbioethics.org/assets/pdfs/GEHR -report-on-regulation.pdf

4. Ethical Guidelines for Biomedical Research on Human Subjects. Indian council of medical research new Delhi (2000).

5. V.V. Oksamytnyi, Legal behavior of a person, p. 175 (1985).

6. E. Moren, La Methode: La Nature de la Nature, p. 464 (2005).

7. V.N. Kudryavtsev, Fighting motives in criminal behavior, p. 200 (2009).

8. A.D. Ursul, New global revolution in science, Issues of philosophy, 8, 104-112 (2019).

9. A.F. Shebanov, On the impact of the right on social development in a state of the whole people, Soviet state and law, 12, 12-16 (1963).

10. L.S. Yavich, Problems of legal regulation of Soviet public relations, p. 171 (1961).

11. A.M. Vitchenko, The method of legal regulation of socialist social relations, p. 160 (1974).

12. S.A. Kurochkin, The effectiveness of legal norms as a condition for the usefulness of legal impact (based on the norms of procedural law), in: Scientific records of Kazan university. Series: human sciences, pp. 70-71 (2020).

13. S.A. Kurochkin, The efficiency of legal standards in theory of legal impact (on the example of civil procedural law), in: Legal regulation mechanism: history and modernity, pp. 270-271 (2019).

14. I.L. Bachilo, Problems of building an information state, p. 594 (2019).

15. E.E. Bogdanova, Legal problems and risks of the genetic revolution: genetic information and discrimination, Lex Russica, 6(151), 18-29 (2019).

16. Criminal Code of Russian Federation (1996).

17. Code of Administrative Violations of the Russian Federation (2001). 
18. A.A. Kostikova, Digital Communication: Historical and Philosophical Analysis, Moscow University Bulletin. Series 7. Philosophy, 5, 49-55 (2019).

19. A.V. Markeeva, O.V. Gavrilenko, Digital platform as a new economic actor and a new instance of social control, Moscow University Bulletin. Series 7. Philosophy, 5, 29-48 (2019).

20. V. M. Zhernova, Subjects of legal relations on the Internet, Bulletin of the South Ural State University. Law Series, 3, 98-101 (2015).

21. L.N. Berg, Information and Psychological Aspect of Legal Influence in Scientific Activities, Russian Juridical Journal, 4(91), 92-100 (2013).

22. L. Berg, The establishment of legal rules as an element of the system of legal influence: An instrumental approach, BRICS Law Journal, 5(3), 114-134 (2018).

23. D.V. Murzin, The legal nature of the results of scientific activities; Russian Law, Education, Practice, Science, 2, 15-24 (2019).
24. A.S. Vasilyev, D.V. Murzin, Trends of Application of Subjective Good Faith in Russian Law: Approaches to Intellectual property, Religación. Revista de Ciencias Sociales y Humanidades, 4(14) (2019).

25. M. Schneider, Intellectual property rights, the new currency, Journal of Intellectual Property Law \& Practice, 14(11), 825-826 (2019).

26. M. Siems, The law and ethics of cultural appropriation, International Journal of Law in Context, 15(4), 408-423 (2019).

27. A.V. Petrov, A.V. Zyryanov, On Some Methodological Approaches in Legal Research (Philosophical, Naturalistic, Positivist Approaches), Bulletin of Tomsk State University, 438, 227-235 (2019).

28. D.V. Gribanov, K.E. Kovalenko, N.E. Kovalenko, The Development of the Information Society, Universidad y sociedad, 10(3), 365-368 (2018). 